\title{
Characterisation of triacylglycerol hydrolase activities in human placenta
}

\author{
Ian J. Waterman ${ }^{\mathrm{a}}$, Neil Emmison ${ }^{\mathrm{b}}$, Asim K. Dutta-Roy ${ }^{\mathrm{a}, *}$ \\ a Rowett Research Institute, Aberdeen AB21 9SB, Scotland, UK \\ b The Robert Gordon University, School of Applied Sciences, Aberdeen, Scotland, UK
}

Received 14 July 1998; revised 18 August 1998; accepted 18 August 1998

\begin{abstract}
Triacylglycerol hydrolase activities were characterised in homogenates, cytosol, and microvillous membranes (MVM) of human placenta. Homogenates of placenta exhibited three distinct triacylyglycerol hydrolase activities with $\mathrm{pH}$ optima 4.5, 6.0 and 8.0. On further fractionation, placental cytosol exhibited both acid cholesterol ester hydrolase ( $\mathrm{pH} 4.5)$ and hormone sensitive lipase ( $\mathrm{pH}$ 6.0) activities, whereas purified placental MVM exhibited two distinct triacylyglycerol hydrolase activities; a minor activity at $\mathrm{pH} 8.0$ and a second major activity at $\mathrm{pH} 6.0$. Triacylglycerol hydrolase activity at $\mathrm{pH} 8.0$ of MVM appeared to be lipoprotein lipase (consistent with criteria such as serum stimulation and salt inhibition), whereas at $\mathrm{pH} 6.0$ the activity was unique in that it was almost abolished by serum, but was not affected by high $\mathrm{NaCl}$ concentrations. Our data, for the first time, demonstrate that human placental MVM, in addition to lipoprotein lipase, contain a newly identified triacylglycerol hydrolase activity at pH 6.0. (C) 1998 Elsevier Science B.V. All rights reserved.
\end{abstract}

Keywords: Human placenta; Triacylglycerol hydrolase activity; Lipoprotein lipase; Fatty acid transport; Free fatty acid; Placental microvillous membrane

\section{Introduction}

The developing fetus requires long chain polyunsaturated fatty acids (LCPUFA) for the formation of structural components of cell membranes, for participation in intracellular signalling, and in the provision of triacylglycerol stores necessary for postnatal life (see reviews [1,2]). During the third trimester of pregnancy, LCPUFA, mainly docosahexaenoic and arachidonic acids, are deposited in large amounts

Abbreviations: LCPUFA, long chain polyunsaturated fatty acids; MVM, microvillous membranes; FFA, free fatty acids; FCS, fetal calf serum; PBS, phosphate-buffered saline

* Corresponding author. Fax: +44 (1224) 716622;

E-mail: adr@rri.sari.ac.uk in the fetal brain and retina [1,2]. Placental transport of maternal plasma LCPUFA is in practice crucial for fetal growth and development because fetal synthesis of these fatty acids is considered to be very low $[1,2]$. The rate of deposition of LCPUFA in the developing fetus depends on their uptake by the placenta from maternal circulation and their subsequent transport to the fetus. We have recently shown that human placenta contains several membrane associated-, and cytosolic fatty acid-binding proteins and these proteins may be involved in placental uptake and subsequent transport of fatty acids to the fetus [3-5]. Of these binding proteins, a $40 \mathrm{kDa}$ plasma membrane fatty acid-binding protein exclusively located in the microvillous membranes, is responsible for placental uptake of maternal LCPUFA [5-7].

Free fatty acids (FFA) in the maternal circulation 
are the major source of fatty acids for transport across the placenta [1,2]. Recent data suggest that fatty acid profiles in the plasma FFA pool, triacylglycerol fatty acid composition as well as lipoprotein profiles change considerably as pregnancy continues in order to support fetal demands for LCPUFA [8-10]. FFA are generated either by intravascular lipolysis of lipoproteins or by the hydrolysis of triacylglycerols in the maternal adipose tissue. Since lipoprotein lipase is exclusively present on the maternal side of the placenta and its activity is increased several fold during the last stages of gestation $[1,11,12]$, thus indicates that placental lipases may play an important role in fatty acid transfer between the mother and the fetus.

Previous studies have examined lipase activity at $\mathrm{pH} 4.0$ for acid cholesterol hydrolase and/or at $\mathrm{pH}$ 8.0 for lipoprotein lipase in crude placental tissue homogenates $[13,14]$. Despite this fact, human placental lipases have not been well characterised. However, at least $50 \%$ of lipolytic activity of placental homogenates may be due to lipoprotein lipase [13]. Placental macrophages have been reported to have the most lipoprotein lipase activity of the placenta, whereas syncytiotrophoblasts have very little activity [15]. Important questions, therefore, still remain unanswered regarding not only the identity of the lipases, but also their location in placental cells. We have recently shown that once FFA are taken up by the placental trophoblasts, docosahexaenoic acid is preferentially incorporated into the triacylglycerol fraction [16,17], but the mechanisms involved in these processes are still not known. Placental lipases could play an important role in packaging and transporting of FFA once they are taken up by syncytiotrophoblasts.

In order to further characterise lipases and their cellular distribution in human placenta, we examined the presence of the triacylglycerol hydrolase activity in crude homogenates, cytosol and purified microvillous membranes of human placenta. We report in this paper, the presence of several triacylglycerol hydrolases, such as acid cholesterol hydrolase, hormone sensitive lipase and lipoprotein lipase in human placenta. In addition to lipoprotein lipase, human placental microvillous membranes contain another, major, triacylglycerol hydrolase activity with optimum activity at $\mathrm{pH}$ 6.0. By important diagnostic criteria, this enzyme activity is distinctly different from authentic lipoprotein lipase. At present, the structure and function of this newly identified enzyme activity at pH 6.0 is not known; however, this may play an important role in feto-placental lipid transport and metabolism.

\section{Materials and methods}

\subsection{Materials}

$\left[1-{ }^{14} \mathrm{C}\right]$ Oleic acid $(55 \mathrm{mCi} / \mathrm{mmol})$ and glycerol tri $\left[9,10(\mathrm{n})-{ }^{3} \mathrm{H}\right]$ oleate $(14 \mathrm{Ci} / \mathrm{mmol})$ were obtained from Amersham, UK. Trypsin (type I, from bovine pancreas), bovine serum albumin (fat free), and fetal calf serum were obtained from Sigma, Poole, UK. All other reagents used were of analytical grade.

\subsection{Placental villous tissue homogenate preparation}

Term human placentas delivered vaginally or by elective caesarean section from otherwise uncomplicated pregnancies were obtained within $1 \mathrm{~h}$ of delivery from Aberdeen Maternity Hospital, Aberdeen. Placental villous tissue homogenate was then prepared as described before [3,4]. Freshly prepared membranes were suspended in phosphate-buffered saline (PBS), pH 7.4, to give a membrane suspension of approximately $5 \mathrm{mg}$ protein $/ \mathrm{ml}$ and stored at $-80^{\circ} \mathrm{C}$ for further use.

Protein was determined by the Bradford method using bovine serum albumin as a standard [18].

\subsection{Placental cytosol preparation}

The tissue was homogenised in buffer containing $10 \mathrm{mM}$ Tris- $\mathrm{HCl}, \mathrm{pH} 7.4$ and $250 \mathrm{mM}$ sucrose. The supernatant from the $10000 \times g$ centrifugation was decanted and the resultant supernatant was again centrifuged for $1 \mathrm{~h}$ at $100000 \times g$ [5]. The resulting cytosolic supernatant was stored at $-80^{\circ} \mathrm{C}$ for further use.

\subsection{Human placental microvillous membrane preparation}

Highly purified microvillous membranes (MVM) 
were prepared from the placenta following a method described previously $[4,5]$. Following removal of chorionic and basal plates, the villous tissue was then excised in small pieces and washed in ice-cold PBS to remove excess blood. The villous tissue was then re-suspended in 5 vols. of ice cold PBS and gently stirred for $30 \mathrm{~min}$. The suspension was then centrifuged for $300 \times g$ for $15 \mathrm{~min}$ and the supernatant decanted through a $250 \mu \mathrm{m}$ pore size nylon mesh. The supernatant was then used as for the purification of MVM [4,5]. The purified MVM were then re-suspended in buffer containing $50 \mathrm{mM}$ Tris- $\mathrm{HCl}, \mathrm{pH}$ $7.4,0.02 \% \mathrm{NaN}_{3}$, and $250 \mathrm{mM}$ sucrose and stored at $-80^{\circ} \mathrm{C}$ for further use.

\subsection{Determination of triacylglycerol hydrolase activity assay}

Triacylglycerol hydrolase activity of placental preparations was determined as described before [19], but with slight modifications. Substrate for the assay was prepared using $250 \mu \mathrm{M}$ glycerol tri $\left[9,10(\mathrm{n})-{ }^{3} \mathrm{H}\right]$ oleate $(5 \mu \mathrm{Ci} / \mu \mathrm{mol})$ in acetone, $10 \mu \mathrm{g}$ phosphatidyl choline/phosphatidyl serine $(1: 1, \mathrm{w} / \mathrm{w})$ in $10 \mathrm{mM}$ Tris- $\mathrm{HCl}, \mathrm{pH} 7.0$, and $100 \mu \mathrm{g}$ of bovine serum albumin in $10 \mathrm{mM}$ Tris- $\mathrm{HCl}, \mathrm{pH}$ 7.0. Under all assay conditions, the amount of acetone was maintained at $2.5 \%(\mathrm{v} / \mathrm{v})$. Placental preparations were then added and incubated with the above mixture in a final volume of $200 \mu \mathrm{l}$. The reaction was stopped after $30 \mathrm{~min}$ by addition of $3.25 \mathrm{ml}$ of methanol/chloroform/heptane (1.40:1.25:1.00 (v/v)) and $1.05 \mathrm{ml}$ of $0.2 \mathrm{M}$ borate-carbonate, $\mathrm{pH} 10.5$. $\left[1-{ }^{14} \mathrm{C}\right]$ oleic acid $(2500 \mathrm{dpm})$ was added to serve as an internal standard. The mixture was vortexed for $30 \mathrm{~s}$ and centrifuged at $750 \times g$ for $20 \mathrm{~min}$. A $0.5 \mathrm{ml}$ of the upper aqueous phase containing $[9,10(n)$ $\left.{ }^{3} \mathrm{H}\right]$ oleate and $\left[1-{ }^{14} \mathrm{C}\right]$ oleic acid was counted on dual channel Packard 1900CA Tri-Carb Liquid Scintillation Analyser (Packard, USA). Triacylglycerol hydrolase activity in all preparations was expressed in units (pmol of $\left[{ }^{3} \mathrm{H}\right]$ oleic acid released/min) per $\mathrm{mg}$ of protein.

$\mathrm{pH}$ dependence of triacylglycerol hydrolase activities of placental preparations were determined by incubating the placental preparations at different $\mathrm{pH}$ values from 3.5 to 9 using different buffer preparations, as described previously [19].

\subsection{Effect of trypsin on triacylglycerol hydrolase activity of $M V M$}

Effect of trypsin on triacylglycerol hydrolase activity of MVM was investigated. Briefly, $100 \mu \mathrm{g}$ MVM was incubated with 316 BAEE ( $N \alpha$-benzoyl-L-arginine ethyl ester) hydrolysing units of trypsin in $50 \mathrm{mM}$ Tris- $\mathrm{HCl}$, pH 8.0 containing $10 \mathrm{mM} \mathrm{CaCl}_{2}$ for $3 \mathrm{~h}$ at $23^{\circ} \mathrm{C}$ in a total volume of $200 \mu \mathrm{l}$. After the incubation, membranes were washed and triacylglycerol hydrolase activity was determined as described above. Parallel experiments were performed under similar conditions with the exclusion of trypsin.

\subsection{Western blot analysis of hormone-sensitive lipase of human placental cytosol}

Monospecific polyclonal antisera against purified hormone sensitive lipase raised in rabbits were kindly supplied by Prof. S.J. Yeaman, Department of Biochemistry and Genetics, University of Newcastle upon Tyne, UK. Western blot analyses of placental homogenates, cytosol and pure MVM were carried out as described before [4]. Polyacrylamide gel electrophoresis of cytosolic proteins in the presence of sodium dodecyl sulphate (SDS) was carried out under reducing conditions on SDS-PAGE gel homogenous 20 (Phast System, Pharmacia, UK). After electrophoresis, proteins were transferred onto a nitrocellulose membrane by diffusion blotting at $70^{\circ} \mathrm{C}$ for $1 \mathrm{~h}$. The membranes were probed for the presence of hormone sensitive lipase by incubating with polyclonal antiserum to this protein. Antibody-antigen complexes were then detected with HRP-anti-IgG fraction of donkey polyclonal antiserum (Scottish Antibody Production Unit).

\section{Results}

\subsection{Identification of triacylglycerol hydrolase activities in human placental crude homogenates and cytosol}

Firstly, triacylglycerol hydrolase activities were investigated in crude placental homogenates. Fig. 1 shows the effect of $\mathrm{pH}$ on placental triacylglycerol hydrolase activity. Three distinctive peaks of triacyl- 
glycerol hydrolase activity were detected at $\mathrm{pH} 4.5$, 8.0 , and a much broader peak in the $\mathrm{pH}$ range 6.0 7.0 , suggesting that two or more enzymatic activities might be present in the crude preparation.

To establish whether the broader peak of enzymatic activity in the $\mathrm{pH}$ range 6.0-7.0 consisted of more than one triacylglycerol hydrolase activity, homogenates of placental villi tissue were centrifuged at $100000 \times g$ for $60 \mathrm{~min}$ to remove subcellular organelles and membrane components. The supernatant was subsequently screened for triacylglycerol hydrolase as shown in Fig. 2. One distinctive peak at $\mathrm{pH}$ 5.0 was detected and a broader peak between $\mathrm{pH} 6.5$ and 7.0 (Fig. 2). Western blot analysis show that the peak between $\mathrm{pH} 6.5$ and 7.0 has immunoreactivity with antibodies raised against human hormone sensitive lipase (84 kDa) (Fig. 3).

\subsection{Triacylglycerol hydrolase activities in placental microvillous membranes}

Macrophages and trophoblasts are two main parenchymal components of the human placenta [20]. Macrophages comprise most of the interstitial cells of the human placental villi and include about $50 \%$ of isolated placental parenchymal cells. Placental

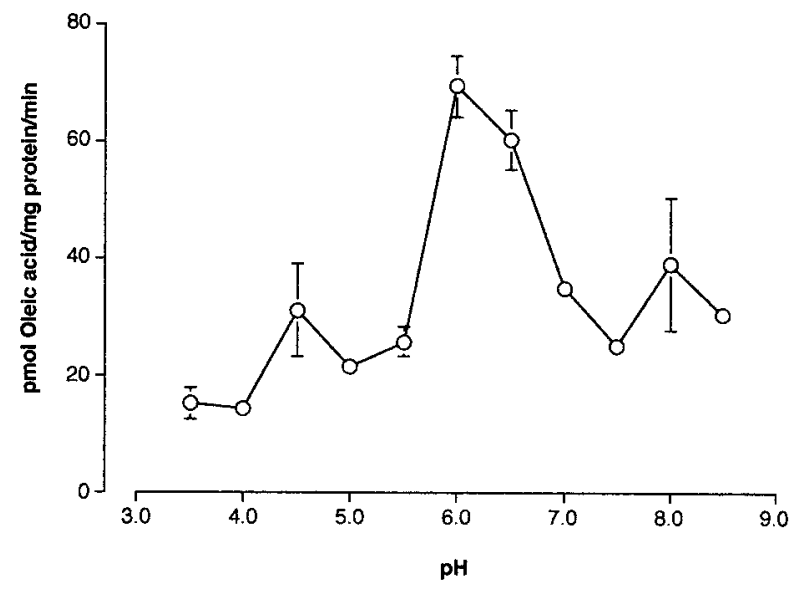

Fig. 1. $\mathrm{pH}$ dependence of triacylglycerol hydrolase activity of human placental homogenates. Crude placental homogenate (20 $\mu \mathrm{g}$ of protein) was incubated with $250 \mu \mathrm{M}$ glycerol $\operatorname{tri}\left[9,10(\mathrm{n})-{ }^{3} \mathrm{H}\right]$ oleate $(5 \mu \mathrm{Ci} / \mu \mathrm{mol})$ for $30 \mathrm{~min}$ at $37^{\circ} \mathrm{C}$. Buffers used: for $\mathrm{pH}$ 3.5-5.6, sodium acetate buffer; for $\mathrm{pH}$ 6.0-8.0, sodium phosphate buffer; for $\mathrm{pH} 8.5-9.0$, glycine- $\mathrm{NaOH}$ buffer. For experimental details please see Section 2. Each point represents the mean of triplicate determinations of three placentas \pm S.E.M.

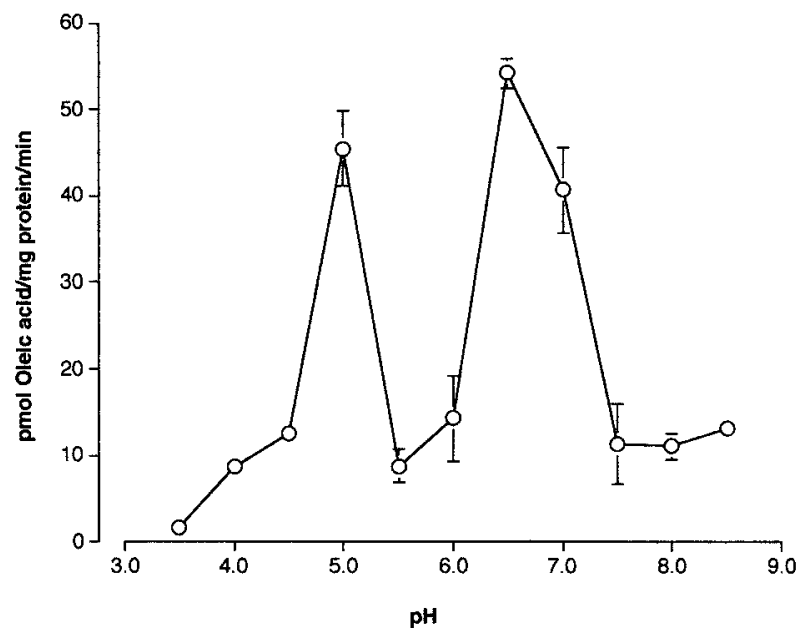

Fig. 2. $\mathrm{pH}$ dependence of triacylglycerol hydrolase activity of human placental cytosol. Placental cytosol $(20 \mu \mathrm{g}$ of protein) was incubated with $250 \mu \mathrm{M}$ glycerol tri[9,10(n)${ }^{3} \mathrm{H}$ ]oleate $(5 \mu \mathrm{Ci} / \mu \mathrm{mol})$ for $30 \mathrm{~min}$ at $37^{\circ} \mathrm{C}$. Buffers used: for $\mathrm{pH}$ 3.5-5.6, sodium acetate buffer; for $\mathrm{pH}$ 6.0-8.0, sodium phosphate buffer; for $\mathrm{pH} 8.5-9.0$, glycine- $\mathrm{NaOH}$ buffer. For experimental details please see Section 2. Each point represents the mean of triplicate determinations of three placentas \pm S.E.M.

macrophages have been reported to contain the majority of lipoprotein lipase activity of the placenta compared with syncytiotrophoblasts [15]. Therefore, placental microvillous membranes were used to screen the triacylglycerol hydrolase activities, using a range of $\mathrm{pH}$ values (Fig. 4). Two clearly distinguishable peaks of triacylglycerol hydrolase activities were identified with $\mathrm{pH} 6.0$ and 8.0. Compared with the activity at $\mathrm{pH} 8.0$, the activity of $\mathrm{pH} 6.0$ was $4-5$ fold higher $(P<0.001, t$-test $)$. Western blot analysis indicated that pure syncytiotrophoblast membranes did not contain hormone sensitive lipase (Fig. 3) suggesting that the activity at $\mathrm{pH} 6.0$ in purified MVM was not due to hormone sensitive lipase activity.

\subsection{Differentiation of the triacylglycerol hydrolase activities in human placental MVM}

To confirm the presence of previously reported lipoprotein lipase in the placental MVM and also to establish whether the triacylglycerol hydrolase activity at $\mathrm{pH} 6.0$ is either unique or related to lipoprotein lipase in terms of its important diagnostic criteria, we investigated the triacylglycerol hydrolase activities in 
A

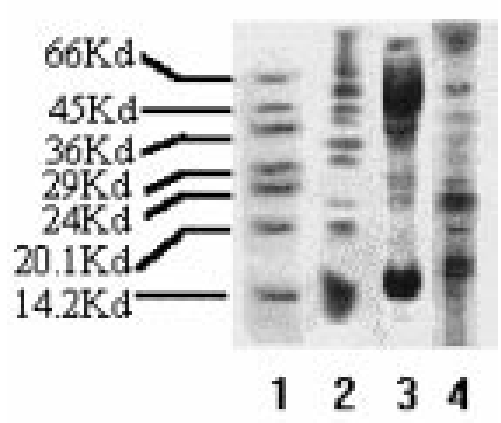

B

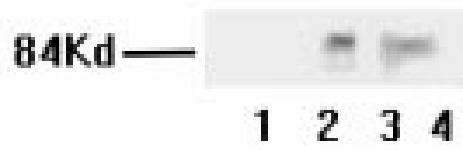

Fig. 3. Western blot analysis of placental crude homogenates, placental cytosol and microvillous membranes. (A) Lane 1, molecular weight protein standards, bovine serum albumin (66 $\mathrm{kDa})$, egg albumin (45 kDa), glyceraldehyde 3 dehydrogenase $(36 \mathrm{kDa})$, carbonic anhydrase $(20 \mathrm{kDa})$ and $\alpha$-lactalbumin $(14.2$ $\mathrm{kDa})$; lane 2 , crude placental homogenates $(15 \mu \mathrm{g})$; lane 3 , placental cytosol $(15 \mu \mathrm{g})$; lane 4 , placental microvillous membranes $(15 \mu \mathrm{g})$. (B) Representative Western blot of the proteins showing immunoreactivity with human placental anti-hormone sensitive lipase antisera. The Western blots were carried out as described in Section 2. The lanes were as for A.

human placental MVM at $\mathrm{pH} 8.0$ and $\mathrm{pH} 6.0$ in the presence of serum and high salt concentrations, and the heparin releasability of triacylglycerol hydrolase activity of MVM.

Heparin releasability of MVM triacylglycerol hydrolase activity was examined by incubating the membranes with heparin for $60 \mathrm{~min}$ at $37^{\circ} \mathrm{C}$, fol- lowed by centrifugation at $100000 \times g$. The relative triacylglycerol hydrolase activities (at pH 6 and 8) in the pellet and supernatant was then determined. Triacylglycerol hydrolase activity at $\mathrm{pH} 8.0$ was almost $84 \pm 7.3 \%$ released $(24.19 \pm 0.26 \mathrm{pmol}$ oleic acid $/ \mathrm{mg}$ protein/min) from the membranes (initial activity $27.19 \pm 4.27 \mathrm{pmol}$ oleic acid/mg protein $/ \mathrm{min}$ ) by heparin treatment whereas the activity at $\mathrm{pH} 6.0$ (initial activity $75.14 \pm 7.6 \mathrm{pmol}$ oleic acid $/ \mathrm{mg}$ protein $/ \mathrm{min}$ ), however, was only partially $(47.0 \pm 19.7 \%)$ released (Table 1). Since lipoprotein lipase is readily released from membranes by heparin [21,22], this indicates that placental MVM contain a unique non-heparinreleasable triacylglycerol hydrolase with $\mathrm{pH}$ optima at 6.0, in addition to heparin-releasable triacylglycerol hydrolase with $\mathrm{pH}$ optima 8.0.

Furthermore, triacylglycerol hydrolase activity of MVM was assayed at $\mathrm{pH} 6.0$ and 8.0, either in the presence or absence of $15 \%(\mathrm{v} / \mathrm{v})$ fetal calf serum (FCS). FCS stimulated the triacylglycerol hydrolase activity at $\mathrm{pH} 8.0$ by as much as 250 times $(0.08 \pm$ $0.3 \mathrm{pmol}$ oleic acid $/ \mathrm{mg}$ protein $/ \mathrm{min}$ vs. $19.8 \pm 0.2 \mathrm{pmol}$ oleic acid/mg protein/min, $P<0.005, n=5$ ). In contrast, however, the triacylglycerol hydrolase activity of MVM at $\mathrm{pH} 6.0(75.14 \pm 0.06 \mathrm{pmol}$ oleic acid $/ \mathrm{mg}$ protein $/ \mathrm{min}$ ) was abolished by the presence of serum $(0.01 \pm 0.002 \mathrm{pmol}$ oleic acid $/ \mathrm{mg}$ protein $/ \mathrm{min}$, $P<0.005, n=7)$. This indicates that triacylglycerol hydrolase activity at pH 8.0 of MVM was a lipoprotein lipase (consistent with criteria such as serum stimulation), whereas at $\mathrm{pH} 6.0$, the activity was unique in that it was almost abolished by serum.

As a final step, the tracylglycerol hydrolase activity at $\mathrm{pH} 8.0$ of MVM was determined in the presence of serum to activate the enzyme to its fullest extent

Table 1

Effect of heparin on release of triacylglycerol hydrolase activities from microvillous membranes of human placenta

$\mathrm{pH} \quad$ Triacylglycerol hydrolase activity ( $\mathrm{pmol}$ oleic acid released/mg protein/min)

Initial activity present in microvillous membranes After heparin treatment

\begin{tabular}{llcl}
\cline { 3 - 4 } & & Membrane & Supernatant \\
\hline 8.0 & $27.19 \pm 4.27$ & $3.87 \pm 0.19^{\mathrm{a}}$ & $24.19 \pm 0.26$ \\
6.0 & $75.14 \pm 7.6$ & $39.83 \pm 1.89^{\mathrm{b}}$ & $35.31 \pm 2.21$ \\
\hline
\end{tabular}

Triacylglycerol hydrolase activities of microvillous membranes (with and without treating with heparin) and their supernatant were determined at pH 6.0 and $\mathrm{pH}$ 8.0, as described in Section 2. Results are expressed as mean \pm S.E.M. $(n=3)$.

${ }^{a} P<0.005$ relative to initial triacylglycerol hydrolase ( $\mathrm{pH} 8.0$ optima) activity of microvillous membranes.

${ }^{\mathrm{b}} P<0.01$ relative to initial triacylglycerol hydrolase ( $\mathrm{pH} 6.0$ optima) activity of microvillous membranes $(t$-test). 


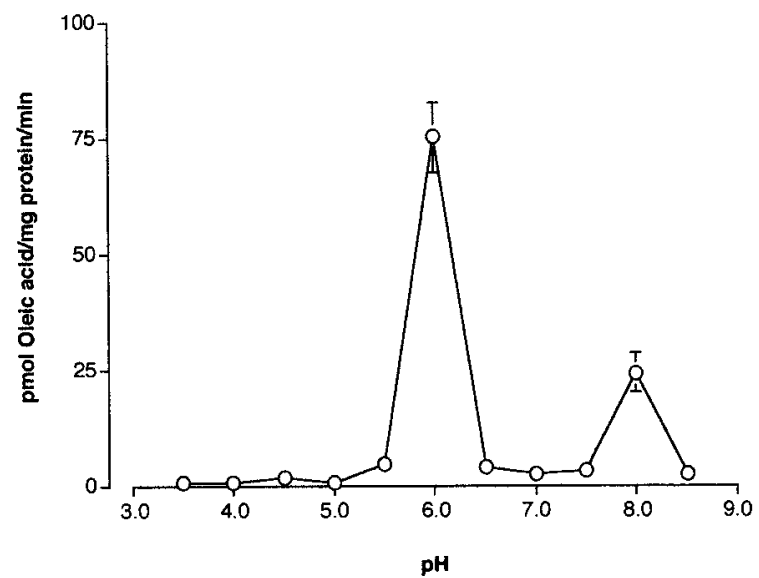

Fig. 4. $\mathrm{pH}$ dependence of triacylglycerol hydrolase activity of human placental microvillous membranes. Placental microvillous membranes $(20 \mu \mathrm{g}$ of protein) were incubated with $250 \mu \mathrm{M}$ glycerol tri[9,10(n)- $\left.{ }^{3} \mathrm{H}\right]$ oleate $(5 \mu \mathrm{Ci} / \mu \mathrm{mol})$ for $30 \mathrm{~min}$ at $37^{\circ} \mathrm{C}$. For experimental details please see Section 2. Each point represents the mean of triplicate determinations of three placentas \pm S.E.M.

and then the effect of $1.0 \mathrm{M} \mathrm{NaCl}$ on hydrolase activity was investigated. Under these incubation conditions, the triacylglycerol hydrolase activity (20.36 $\pm 1.03 \mathrm{pmol}$ oleic acid $/ \mathrm{mg}$ protein $/ \mathrm{min})$ at $\mathrm{pH}$ 8.0 was inhibited by up to $80 \%(4.17 \pm 0.02, P<0.05$, $n=5)$ whereas $\mathrm{NaCl}$ was without effect on the triacylglycerol hydrolase activity of MVM at $\mathrm{pH} 6.0$ $(70.14 \pm 0.10$ vs. $69.26 \pm 0.6 \mathrm{pmol}$ oleic acid $/ \mathrm{mg}$ protein/min, $P>0.5, n=7$ ).

Trypsin digestion of MVM abolished triacylglycerol hydrolase activity at pH 6.0 by $80 \%(P<0.05)$, whereas the activity at $\mathrm{pH} 8.0$ was abolished only by $20 \%(P=0.05)$.

All the above studies demonstrated clearly that placental MVM contain a new triacylglycerol hydrolase activity with $\mathrm{pH} 6.0$ optimum, in addition to previously described lipoprotein lipase with $\mathrm{pH} 8.0$ optima [14].

\section{Discussion}

The studies presented in the paper attempt to further characterise triacylglycerol hydrolase activities in human placenta. We have detected the presence of cholesterol acid hydrolase, hormone sensitive lipase (on the basis of immunological data only) and lipoprotein lipase which are, however, reported to occur in human placenta. In addition to lipoprotein lipase ( $\mathrm{pH}$ 8.0), MVM contain, hitherto unknown, a major triacylglycerol hydrolase activity with a $\mathrm{pH} 6.0$ optima. In contrast to lipoprotein lipase, this enzyme activity was only partially released from the membranes by heparin treatment, was inactivated by serum and was unaffected by the presence of high concentrations of $\mathrm{NaCl}$. The triacylglycerol hydrolysing activity at pH 6.0 represented up to $80 \%$ of the total triacylglycerol hydrolysing capability of the MVM. All these data suggest that presence of a unique, but major, lipase activity in MVM hitherto unknown at pH 6.0 in human placenta. By important diagnostic criteria $(\mathrm{pH}$ optima, heparin releasability, serum and salt effect), this activity was clearly different from authentic lipoprotein lipase. Previous studies indicated that placental lipoprotein lipase may not be authentic lipoprotein lipase based on one important criteria, i.e. lack of serum stimulation of placental lipase [13,21]. However, these studies were performed using crude placental homogenates and therefore they could not identify the important and major triacylglycerol hydrolase activity at $\mathrm{pH} 6.0$ on MVM. Our study demonstrates that authentic lipoprotein lipase activity is rather a minor activity in purified MVM, which is consistent with the findings of Bonet et al. [15].

Serum stimulation of lipoprotein lipase is a physiologically relevant phenomenon, residing in the apolipoprotein (apo) C-II - a component of chylomicron, VLDL and HDL. It enables the lipoprotein lipase, acting at a site on the luminal surface of the capillary, to be maximally active in the presence of its substrates, triacylglycerol-rich lipoproteins [22]. Therefore, it is possible that the inhibitory effect of serum on triacylglycerol hydrolase activity at $\mathrm{pH} 6.0$ of MVM may not allow it to act on maternal lipoproteins, but only on intracellular triacylglycerol stores in placenta. The mode of fatty acid transport of placenta to the fetus is not well known, but some studies suggest that FFA are released from the placenta [23,24]. If it is true, then this membrane-bound triacylglycerol hydrolase (optima $\mathrm{pH}$ 6.0) may play an important role in releasing FFA by hydrolysing the placental stored triacylglycerol. This unique triacylglycerol hydrolase activity at $\mathrm{pH} 6.0$ therefore may be involved in the packaging and/or releasing 
FFA from the placenta, whereas lipoprotein lipase, which is mostly present in placental macrophages, may be responsible for hydrolysis of maternal plasma lipoproteins as suggested by Bonet et al. [15].

Apart from lipoprotein lipase, other membrane bound lipases, such as microsomal triacylglycerol hydrolase(s), have been reported to occur in many tissues $[19,25,26]$. Although the function of the microsomal triacylglycerol hydrolase activity is still not clearly understood, they may be involved in mobilisation of intracellular triacylglycerol for VLDL assembly and secretion [19,25]. Microsomal triacylglycerol hydrolase(s) appear to be different from this human placental MVM triacylglycerol hydrolase activity (pH 6.0) both in their $\mathrm{pH}$ optima (varies from $\mathrm{pH} 4.5$ to $\mathrm{pH} 8.0$ ) and membrane location $[25,26]$. However, further work, such as molecular characterisation of the newly identified activity at $\mathrm{pH} 6$ in MVM, is required for definitive conclusions as to its relationship with lipases and its role in placental lipid transport and metabolism.

Previous studies have shown the lipoprotein lipase ( $\mathrm{pH}$ 8.0) was not affected in clinical conditions, such as diabetes, whereas acid cholesterol hydrolase activity ( $\mathrm{pH} 4.0)$ was increased [27]. However, no information was available on $\mathrm{pH} 6.0$ activity; therefore, further work is now in progress to examine the activity of $\mathrm{pH} 6.0$ activity under these clinical conditions.

In conclusion, we report for the first time the presence of a unique, but major, triacylglycerol hydrolase activity in purified microvillous membranes of human placenta. This newly identified activity may play a major role in transporting placental derived maternal FFA to the fetus.

\section{Acknowledgements}

I.J.W. is a recipient of a $\mathrm{PhD}$ fellowship from the Boyd Orr Research Centre, Aberdeen Research Consortium. This work was supported in part by the Scottish Office Agriculture, Environment and Fisheries Department (SOAEFD). The authors are grateful to Prof. S.J. Yeaman, Department of Biochemistry and Genetics, University of Newcastle upon Tyne, UK for providing anti-hormone sensitive lipase antiserum used in this study.

\section{References}

[1] A.K. Dutta-Roy, Fatty acid transport and metabolism in the feto-placental unit and the role of fatty acid-binding proteins, J. Nutr. Biochem. 8 (1997) 548-557.

[2] S. Innis, Essential fatty acids in growth and development, Prog. Lipid Res. 30 (1986) 39-103.

[3] F.M. Campbell, S. Taffesse, M.J. Gordon, A.K. Dutta-Roy, Plasma membrane fatty acid-binding protein from human placenta: identification and characterisation, Biochem. Biophys. Res. Commun. 209 (1995) 1011-1017.

[4] F.M. Campbell, A.K. Dutta-Roy, Plasma membrane fatty acid-binding protein $\left(\mathrm{FABP}_{\mathrm{pm}}\right)$ is exclusively located in the maternal facing membranes of the human placenta, FEBS Lett. 375 (1995) 227-230.

[5] F.M. Campbell, P. Bush, J.H. Veerkamp, A.K. Dutta-Roy, Distribution of membrane associated- and cytoplasmic fatty acid binding proteins in human placenta, Placenta 19 (1998) 409-415.

[6] F.M. Campbell, M.J. Gordon, A.K. Dutta-Roy, Preferential uptake of long chain polyunsaturated fatty acids by isolated human placental membranes, Mol. Cell. Biochem. 155 (1996) 77-83.

[7] F. Campbell, M.J. Gordon, A.K. Dutta-Roy, Placental membrane fatty acid-binding protein preferentially binds arachidonic and docosahexaenoic acids, Life Sci. 63 (1998) 235-240.

[8] C. Benassayag, T.M. Mignot, M. Haourigui, C. Cive, J. Hassid, B. Carbonne, E.A. Nunez, F. Ferre, High polyunsaturated fatty acids, thromboxane $\mathrm{A}_{2}$ and alpha-fetoprotein concentrations at the human feto-maternal interface, J. Lipid Res. 38 (1997) 276-286.

[9] L. Fahraeus, U. Larsson-Cohn, L. Wallentin, Plasma lipoproteins including high density lipoprotein subfractions during normal pregnancy, Obstet. Gynecol. 66 (1985) 468-472.

[10] J.J. Alvarez, A. Montelongo, A. Iglesia, M.A. Lasuncion, E. Herrera, Longitudinal study on lipoprotein subclass, and postheparin lipases during gestation in women, J. Lipid Res. 37 (1996) 299-308.

[11] O. Huter, H.J. Wolf, A. Schnetzer, K. Pfalller, Lipoprotein lipase, LDL receptors and Apo-lipoporteins in human fetal membranes at term, Placenta 18 (1997) 707-715.

[12] G. Desoye, E. Shafrir, Placental lipid metabolism and transport, Mol. Asp. Med. 15 (1994) 575-590.

[13] S. Mallov, A.A. Alousi, Lipoprotein lipase activity of rat and human placenta, Proc. Soc. Exp. Biol. Med. 119 (1965) 301-306.

[14] B.K. Burton, H.W. Mueller Jr., Purification and properties of human placental acid lipase, Biochim. Biophys. Acta 618 (1980) 449-460.

[15] B. Bonet, J.D. Brunzell, A.M. Gown, R.H. Knoop, Metabolism of very low density lipoprotein triglyceride by human placental cells: the role of lipoprotein lipase, Metabolism 41 (1992) 596-603.

[16] F.M. Campbell, A. Clohessy, M.J. Gordon, K.R. Page, A.K. Dutta-Roy, Uptake of long chain fatty acids by human pla- 
cental choriocarcinoma (BeWo) cells: role of plasma membrane fatty acid-binding protein, J. Lipid Res. 38 (1997) 2558-2568.

[17] J. Crabtree, M.J. Gordon, F.M. Campbell, A.K. Dutta-Roy, Differential distribution and metabolism of arachidonic acid and docoshexaenoic acids by human placental cells, Mol. Cell. Biochem. 185 (1998) 205-212.

[18] M.M. Bradford, A rapid method for the determination of the microgram quantities of protein utilizing the principle of protein-dye binding, Anal. Biochem. 72 (1976) 248-254.

[19] R.A. Coleman, E.B. Haynes, Differentiation of microsomal from triacylglycerol lipase activities in rat liver, Biochim. Biophys. Acta 751 (1983) 230-240.

[20] M. Castellucci, P. Kaufmann, Hofbauer cells, in: K. Benirschke, P. Kaufmann, (Eds.), Pathology of the Human Placenta, Springer, London, 1990, pp. 71-80.

[21] R.A. Clegg, Placental lipoprotein lipase activity in the rabbit, rat and sheep, Comp. Biochem. Physiol. 69B (1981) 585591.
[22] P. Nilsson-Ehle, A.S. Garfinkel, M.C. Schotz, Lipolytic enzymes and plasma lipoproteins, Annu. Rev. Biochem. 49 (1980) 667-693.

[23] R.A. Coleman, E.B. Haynes, Synthesis and release of fatty acids by human trophoblast cells in culture, J. Lipid Res. 28 (1987) 1335-1341.

[24] E. Shafrir, V. Barash, Placental function in maternal-fetal fat transport in diabetes, Biol. Neonat. 51 (1987) 102-112.

[25] R. Lehner, R. Verger, Purification and characterization of a porcine microsomal triacyglycerol hydrolase, Biochemistry 36 (1997) 1861-1868.

[26] M.C. Cabot, S. Gatt, The hydrolysis of triacylglycerol and diacyl glycerol by a rat brain microsomal lipase with an acidic pH optima, Biochim. Biophys. Acta 530 (1978) 508512

[27] S. Kaminsky, C.P. Sibley, M. Maresh, C.R. Thomas, S.W. Dsouza, The effects of diabetes on placental lipase activity in the rat and human, Pediatr. Res. 30 (1991) 541-543. 